\title{
THE RELATIVE EFFECTIVENESS OF THE KURAPUNCTUR AND POINT LOCAL ABDOMEN ACUPUNCTURE THERAPY IN THE REDUCTION OF WAIST CIRCUMFERENCE IN OBESE PATIENTS
}

\author{
Heni Nur Kusumawati, Risna Widowati \\ Diploma III of Acupuncture, School of Health Polytechnics, \\ Ministry of Health Surakarta
}

\begin{abstract}
Background: Obesity is a pathological state as a result of the consumption of food that is far exceeding the needs (psychobiological cues for eating) so there is hoarding an excessive fat than is necessary for bodily functions. Obesity can raise cholesterol level, triglyceride level, insulin resistance, and the risk of high blood pressure, coronary heart disease, ischemic stroke, and type 2 diabetes mellitus. Acupuncture therapy may be an option to handle problems related to obesity, one with abdominal acupuncture techniques. This study aimed to determinethe effectiveness of kurapunctur and point local abdomen acupuncture therapy accompanied by a low calorie and fat diet in the reduction of waist circumference in obese patients.

Subjects and Method: This was a quasi experiment conducted at Kusuma Husada clinic, Surakarta, Central Java, from July to August 2017. A sample of 32 obesity patients was allocated into two groups: (1) The experiment group who received kurapuncture therapy, (2) The control group who received acupuncture therapy in the local point of the abdomen. Acupuncture therapy was carried out for 10 times. All of the study subjects received low calories and low fat diet. The dependent variable was waist circumference. The independent variable was abdominal acupuncture therapy. Waist circumference was measured by measuring tape. The data were analyzed by Mann-Whitney test.

Results: The reduction in waist circumference is greater in the experiment group (mean $=22.9$ ) than in the control group (mean=10.1) with $\mathrm{p}<0.001$.

Conclusion: Kurapuncture therapy is more effective than acupuncture therapy in the local point of the abdomen in reducing waist circumference in obese patients.
\end{abstract}

Keywords: kurapuncture, waist circumference, obesity

\section{Correspondence:}

Heni Nur Kusumawati. Diploma III of Acupuncture, School of Health Polytechnics, Ministry of Health Surakarta, Central Java.

Email: heninurkusumawati@yahoo.com.

Mid-International Conference on Public Health, Best Western Premier Hotel, Solo, Indonesia, 18-19 April 2018 | 254 https://doi.org/10.26911/mid.icph.2018.05.16 